\title{
Emotional and Behavioral Problems and Psychosocial Skills in Adolescents in Residential Care
}

\author{
Joana Campos ${ }^{1}\left[\right.$ D Maria Barbosa-Ducharne ${ }^{1} \cdot$ Pedro Dias $^{2} \cdot$ Sónia Rodrigues $^{1} \cdot$ Ana Catarina Martins $^{1}$. \\ Mariana Leal ${ }^{1}$
}

Published online: 3 January 2019

(c) Springer Science+Business Media, LLC, part of Springer Nature 2019

\begin{abstract}
Research suggests that mental health problems in adolescents in residential care (RC) are more prevalent than for youth in the community, and that psychosocial competencies are protective factors of mental health. This study compared adolescents in RC in Portugal, with a Portuguese community sample on the incidence of mental health problems and psychosocial skills, explored gender differences and the relationships between mental health problems and psychosocial competencies. Four hundred and forty-three adolescents in RC participated. Results showed that the RC adolescents had higher levels of mental health problems lower academic achievement, a poorer social support network, but were more involved in sports and hobbies, household chores than the adolescents in the normative sample. Gender differences were observed. Psychosocial skills were negatively correlated with mental health problems. These findings indicate an urgent need in Portugal for early screening of mental health problems and socio-cognitive interventions for youth in RC.
\end{abstract}

Keywords Residential care · Emotional and behavioral problems · Psychosocial skills · ASEBA battery · Adolescents · Portugal

Children and adolescents who cannot grow up with their parents for whatever reason are an especially vulnerable group (Fernández-Daza \& Fernández-Parra, 2012). In Portugal, most children and adolescents removed from their birth families are placed in residential care (RC), accounting for 6553 children, according to 2017 data (National Institute for Social Security (ISS, IP), 2018).

$\mathrm{RC}$ is a context within the Child Protection System where a child is placed in an institution with the appropriate facilities and permanent professional staff who can ensure suitable care for the needs of emotionally and behaviorally troubled children, allowing for their education, wellbeing and overall development (article 49, Law for the Protection of Children and Youth in Danger [LPCJP], latest review Law 142/2015). Different RC contexts provide different levels

Joana Campos

joanacampos.psi@gmail.com

1 Faculty of Psychology and Education Sciences, University of Porto, Porto, Portugal

2 Faculty of Education and Psychology, Universidade Católica Portuguesa, Research Centre for Human Development, Porto, Portugal of care and individualized attention to each child's needs (Fernández-Daza \& Fernández-Parra, 2012). Many RC contexts attend to a child's basic needs, but frequently ignore their emotional ones (Eapen, 2009). In a neurobiological study on the impact of the lack of attention given to children in RC, Smyke, Zeanah, Fox, Nelson, and Guthrie (2010) concluded that institutionalization influences the development of the child's brain, accounting for cognitive and social deficits. Physical and emotional deprivation suffered by children in RC can result in high rates of psychosocial (Álvares \& Lobato, 2013; Reijneveld, Brugman, Verhulst, \& Verloove-Vanhorick, 2005; Rutter, 2000) and internalization/ externalization problems (Simsek, Erol, Oztop, \& Munir, 2007).

Risks associated with RC and the early adversity resulting in the removal from the birth family, such as high levels of harsh parental punishment, maltreatment, family stress (Campbell, Shaw, \& Gilliom, 2000) and parental negligence (Mäntymaa et al., 2012) are interrelated and cumulative (Gutman, Sameroff, \& Cole, 2003). Research has shown that the total number of these risk factors is the most important predictor of the child's development (Appleyard, Egeland, van Dulmen, \& Sroufe, 2005). 
In fact, $\mathrm{RC}$ has been considered a risk factor for potentially having a negative impact on childrens' psychological development, behavior, and mental health (Rutter, 2000). Several studies have shown the higher prevalence of mental health problems in adolescents in $\mathrm{RC}$, when compared to those living in a family context (Erol, Simsek, \& Munir, 2010; Gearing, Schwalbe, MacKenzie, Brewer, \& Ibrahim, 2014; Janssens \& Deboutte, 2009; Kjelsberg \& Nygren, 2004; Marinlovic \& Backovic, 2007; Schmid, Goldbeck, Nuetzel, \& Fegert, 2008). Mental health problems' prevalence data reported in different studies range from 43 to $86 \%$ (Bronsard et al., 2011; Janssens \& Deboutte, 2009; Jozefiak et al., 2016; Oliván, 2002; Sempik, Ward, \& Darker, 2008; Simms, Dubowitz, \& Szilagyi, 2000). Furthermore, girls tend to show more mental health problems when compared to boys, both in RC (Baker, Archer, \& Curtis, 2007) and normative samples (Abad, Forns, \& Gómez, 2002). Moreover, research (Behen, Helder, Rothermel, Solomon, \& Chugani, 2008; Fernández-Daza \& Fernández-Parra, 2012) has shown that adolescents in RC present lower academic achievement, although a recent study (Huefner, Ringle, Thompson, \& Wilson, 2018) has concluded that adolescents who were behind grade level when placed in RC and facing significant academic challenges, experienced significant gains during their stay in the program (at least 6 months).

Considering that psychosocial skills are protective factors influencing the impact of mental health problems on one's individual functioning (Achenbach, Dumenci, \& Rescorla, 2002; Broberg et al., 2001; Marinlovic \& Backovic, 2007), it is essential to identify and focus on their development in RC youth. Psychosocial skills are acquired in different life contexts promoting different strategies and behaviors, which are developed when coping with positive and negative experiences (Ison-Zintilini \& Morelato-Giménez, 2008). Positive psychosocial skills allow for the promotion of healthier cognitive and emotional behaviors (Ison-Zintilini \& Morelato-Giménez, 2008) and are often associated with hobbies outside an academic context (Sãfvenbom \& Sandahl, 2000). In the current study, psychosocial skills will be scored using the ASEBA battery (Achenbach \& Rescorla, 2001), which includes different activities (e.g. sports, hobbies and household chores) and social skills (e.g. relationships with friends, siblings, parents, and other significant adults as well as participation in other groups).

Regarding overall activities, adolescents in RC seem to get involved in more sports, hobbies and household or community chores than those in normative samples and report being more able to perform them (Fernández-Daza \& Fernández-Parra, 2012). Hobbies promote opportunities to try, fail and search for alternatives, experience satisfaction, freedom and autonomy (Larson \& Kleiber, 1993) and a integration in the community which is very important for adolescents in RC (Sãfvenbom \& Sandahl, 2000). When considering social skills, social support networks for adolescents in RC are often reduced and going into an institution might result in the disruption of previous, important social ties (Bravo \& del Valle, 2003). Prosocial behavior development plays a critical role in self-confidence, cognitive and emotional self-regulation and general social wellbeing (IsonZintilini \& Morelato-Giménez, 2008; Sandoval, Lemos, \& Vallejo, 2006). Some studies (e.g. Eapen, 2009; Simms et al., 2000) have concluded that children in RC show deficits in social competence. This may be due to the problems and challenges they faced prior to being removed from their family homes, or that RC might present fewer opportunities to establish and maintain close and personal relationships, mainly because of the logistics of the RC center, namely, large groups of children with the same care giver (Erickson, Crosnoe, \& Dornbusch, 2000; Marinlovic \& Backovic, 2007). As adolescents in RC do not frequently have the opportunity to relate to significant adults, they tend to have a higher number of peers and peer groups become more relevant (Bravo \& del Valle, 2003).

Considering the high number of children in RC in Portugal and the high incidence of emotional and behavioral problems in this population reported in international research (e.g. Erol et al., 2010; Gearing et al., 2014; Janssens \& Deboutte, 2009; Kjelsberg \& Nygren, 2004; Marinlovic \& Backovic, 2007; Schmid et al., 2008), as well as the scarcity of data on the skills of Portuguese adolescents in RC, the goals of this study are to: (1) compare adolescents in $\mathrm{RC}$ to a national normative sample regarding emotional and behavioral problems and psychosocial skills (participation in activities, social and family contact and academic performance); (2) identify differences associated to gender in adolescents in $\mathrm{RC}$ regarding emotional and behavioral problems and psychosocial skills; (3) explore the existing relationships between emotional and behavioral problems and psychosocial skills in adolescents in RC.

\section{Method}

\section{Participants}

Four hundred and forty-three adolescents (50.1\% female), aged $11-18(M=15.42, S D=2.33)$, participated in this study. They had been placed in 45 Portuguese RC centers for an average of 39 months ( $S D=38.92$, ranging from 1 to 192 months). Some of them ( $\mathrm{n}=172,38.8 \%)$ had previously already been placed in other RC centers ranging from 1 to 154 months $(M=8.07, S D=21.39)$.

The participating adolescents were in RC due to: negligence $(n=195,44 \%)$, lack of parental supervision $(n=103$, $23.2 \%)$, abuse $(\mathrm{n}=54,12.2 \%)$, deviant parental behavior $(n=42,9.5 \%)$ and domestic violence $(n=27,6.1 \%)$. Three 
hundred and ninety-six (89.4\%) of them had one or more siblings, but only $28.2 \%$ had been placed in the same center.

A hundred and fifty-one participants were in centers just for boys, 151 were in institutions for girls and 141 in mixed-gender RC centers. Two hundred and twenty-two were in large centers (with over 24 adolescents), 161 were in medium sized homes (13 to 24 adolescents) and 60 of them were in smaller centers (up to 12 adolescents). There was no association between the gender type and the size of the center, $\chi^{2}(4)=3.79, p=.435$.

The normative sample used for comparison is the national representative sample that allowed for the validation and standardization of the ASEBA battery in Portugal (Achenbach et al., 2014), and was defined following a stratified random sampling method, which considered the distribution of the Portuguese population by country region, gender and age. This sample is made up of 1466 adolescents (51.3\% female), aged $11-18(M=14.33, S D=2.22)$, living with at least one birth parent.

\section{Instruments and Measures}

The Youth Self-Report (YSR; Achenbach et al., 2014) is a tool designed to be completed by adolescents who are 11-18 years old, allowing for the assessment of their own psychosocial competencies and emotional and behavioral problems in a standardized format (social competence and problem scales). Reliability and validity studies have shown the YSR to be a useful and effective instrument for studying emotional and behavioral problems in young people.

The YSR is, therefore, a screening tool for the identification of adolescents with behavioral or emotional problems, which are potential predictors of different levels of clinical disorders. It is composed of two sections: the first one corresponds to emotional and behavioral problems, which constitute two broadband behavior syndromes, termed internalizing and externalizing; the second section includes a social competence scale exploring social activities (sports, hobbies, household chores), social interests (participation in clubs, number of close friends and familiar contact), and academic achievement. Table 1 presents the reliability Cronbach's alpha values of all the YSR scales obtained in the standardization of the ASEBA battery for Portugal, as well as the reliability Cronbach's alpha values of the scales in the present study.

Sociodemographic data were collected using PIP (Pedido de Informação Prévio [Initial Information Request]). This is part of the Portuguese Comprehensive Assessment System of Residential Care Quality (ARQUA-P, Rodrigues, Barbosa-Ducharne, \& Del Valle, 2015) and permits collecting
Table 1 Internal consistency in YSR scales (Cronbach's alpha)

\begin{tabular}{lll}
\hline YSR scales & $\begin{array}{l}\text { National sample } \\
\alpha\end{array}$ & $\begin{array}{l}\text { Study sample } \\
\alpha\end{array}$ \\
\hline Empirically based syndrome scales & & \\
Anxiety/depression (A/D) & 0.738 & 0.821 \\
Withdrawal/depression (W/D) & 0.605 & 0.672 \\
Somatic complaints (SC) & 0.706 & 0.822 \\
Social problems (SP) & 0.582 & 0.768 \\
Thought problems (TP) & 0.661 & 0.807 \\
Attention problems (AP) & 0.634 & 0.735 \\
Rule-breaking behavior (R-BB) & 0.589 & 0.827 \\
Aggressive behavior (AB) & 0.791 & 0.869 \\
DSM-oriented scales & & \\
Affective problems & 0.683 & 0.810 \\
Anxiety problems & 0.546 & 0.596 \\
Somatic problems & 0.635 & 0.805 \\
Attention deficit/hyperactivity problems & 0.731 & 0.715 \\
Oppositional defiant problems & 0.633 & 0.670 \\
Conduct problems & 0.733 & 0.864 \\
Other scales & & 0.972 \\
Internalizing problems (IP) & 0.840 & 0.953 \\
Externalizing problems (EP) & 0.851 & 0.911 \\
Total problems (TP) & 0.929 & 0.961 \\
Activities scales & 0.913 & 0.951 \\
Social scales & 0.597 & 0.672 \\
Academic scale & & 0.95 \\
\hline & & \\
& &
\end{tabular}


data related to the children and youth in care, such as date of birth, age, gender, schooling, health, medical care, family members, time in care, age at placement, reasons for placement.

\section{Procedures}

The Ethic Committee of the University of Porto approved the study procedures, assuring the respect of all research deontological and ethical principles. Prior to each data collection visit, the RC center board was asked to sign an informed authorization statement of consent allowing for participation in the study. Moreover, individual participation was strictly voluntary and the use of study-specific codes ensured the anonymity of all the participants. The selection criteria of the participants included: being over ten, no indication of communication problems preventing being interviewed, having been placed in the RC center for at least 2 months. During the interviews, each adolescent participant was questioned about his/her life in care and specifically about the existence of a significant caregiver or adult with whom she/he had a close relationship with in the RC center. After the interviews, the adolescents filled in the YSR.

Data were analyzed with IBM SPSS-version 23 software (IBM Corp, 2014). Student $T$ tests were used in the comparison analyses with normative data (Achenbach et al., 2014) and Pearson correlations were used to explore existing relationships between the study variables.

\section{Results}

\section{Comparison of Self-Report Measures and Normative Sample}

Table 2 shows that for all YSR scales of emotional and behavioral problems, RC youth were statistically different from the normative sample $(p<.001)$. Adolescents in $\mathrm{RC}$ reported more emotional and behavioral problems than their peers living in a family context. Significant differences in most of the YSR psychosocial skills scales were also observed. On average, adolescents in RC reported practicing sports for a longer time/greater frequency (but not more sports nor being more skilled in sports), and also being more engaged and skilled in hobbies. Regarding household chores, $\mathrm{RC}$ youth reported that they performed more chores and had more commitments than did the normative sample.

Adolescents in RC reported less involvement in clubs than the normative sample, but also reported having more close friends and spending more time with peers and less with siblings, parents and other significant adults. Only 246 adolescents $(55.5 \%)$ could name a significant caregiver or adult with whom they had a close relationship. They also report being less able to perform tasks on their own. Academically, at the time of evaluation, their achievement is poorer than the normative sample.

\section{Gender Differences in Self-Report Measures}

Table 3 shows gender differences in self-report measures on emotional and behavioral problems in adolescents in RC. Female adolescents reported higher scores in anxiety/depression, withdrawal/depression, somatic complaints, thought, attention, affective, anxiety and somatic problems, as well as in internalizing problems and total problems variables. Male adolescents had higher scores in oppositional defiant and conduct problems.

Regarding activities and psychosocial skills, there are some statistically significant gender differences. Female adolescents perform more household chores whereas male adolescents are involved in more clubs, have more close friends, more contacts with siblings, parents and other significant adults, as well as reporting that they are more capable of performing tasks on their own.

\section{Correlations Between Self-Report Problem Behaviors and Competence Measures}

Table 4 shows Pearson correlations between variables related to self-report problem behaviors and skills. The number of sports practiced and hobbies carried out by adolescents in RC are negatively and significantly correlated to oppositional defiant behavior and externalizing problems. The number of household chores is also negatively and significantly correlated to oppositional defiant behavior, aggressive behavior, externalizing problems and the total number of problems.

Regarding social activities, participation in clubs is negatively and significantly correlated to withdrawal/depression, whereas the number of close friends is positively and significantly correlated to oppositional defiant behavior. Contact with siblings is negatively and significantly correlated with anxiety/depression, aggressive behavior and internalizing problems. Interaction with parents is negatively and significantly correlated with most self-report problem behaviors, namely, anxiety/depression, somatic complaints, thought and attention problems, oppositional defiant behavior, aggressive behavior, internalizing and externalizing problems, as well as the total number of problems. Contact with other significant adults is negatively and significantly correlated to anxiety/depression, withdrawal/depression, somatic complaints, social, attention and internalizing problems, as well as the total number of problems. Academic achievement is negatively and significantly correlated to withdrawal/depression, attention problems and oppositional defiant behavior. 
Table 2 Sample differences in self-report measures

\begin{tabular}{|c|c|c|c|c|c|c|}
\hline & $\begin{array}{l}\text { National sample } \\
(\mathrm{N}=1442) \\
\text { Mean }(\mathrm{SD})\end{array}$ & $\begin{array}{l}\text { Study sample } \\
(\mathrm{N}=443) \\
\text { Mean }(\mathrm{SD})\end{array}$ & $t(442)$ & $p$ & $95 \% \mathrm{CI}$ & $d$ \\
\hline Anxiety/depression & $5.72(3.70)$ & $8.41(5.17)$ & 10.95 & .000 & {$[2.21 ; 3.17]$} & -0.598 \\
\hline Withdrawal/depression & $3.68(2.44)$ & $6.00(3.13)$ & 15.62 & .000 & {$[2.03 ; 2.62]$} & -0.827 \\
\hline Somatic complaints & $3.08(2.65)$ & $5.41(4.16)$ & 11.78 & .000 & {$[1.94 ; 2.72]$} & -0.668 \\
\hline Social problems & $2.50(2.18)$ & $5.11(3.86)$ & 14.21 & .000 & {$[2.25 ; 2.97]$} & -0.833 \\
\hline Thought problems & $3.05(2.84)$ & $6.65(4.82)$ & 15.73 & .000 & {$[3.15 ; 4.05]$} & -0.910 \\
\hline Attention problems & $4.46(3.08)$ & $7.02(3.69)$ & 14.63 & .000 & {$[2.22 ; 2.91]$} & -0.753 \\
\hline Rule-breaking behavior & $3.04(2.69)$ & $7.41(5.27)$ & 17.46 & .000 & {$[3.88 ; 4.87]$} & -1.044 \\
\hline aggressive behavior & $6.02(4.20)$ & $10.64(6.58)$ & 14.80 & .000 & {$[4.01 ; 5.24]$} & -0.837 \\
\hline affective problems & $3.71(3.06)$ & $7.98(5.10)$ & 17.63 & .000 & {$[3.80 ; 4.75]$} & -1.015 \\
\hline anxiety problems & $3.25(1.97)$ & $4.29(2.39)$ & 9.14 & .000 & {$[0.82 ; 1.26]$} & -0.475 \\
\hline Somatic problems & $1.72(1.84)$ & $3.18(3.09)$ & 9.93 & .000 & {$[1.17 ; 1.75]$} & -0.574 \\
\hline Attention deficit/hyperactivity problems & $4.07(2.72)$ & $5.78(3.10)$ & 11.64 & .000 & {$[1.42 ; 2.00]$} & -0.586 \\
\hline Oppositional defiant problems & $2.68(1.76)$ & $3.75(2.26)$ & 9.95 & .000 & {$[0.86 ; 1.28]$} & -0.528 \\
\hline Conduct problems & $2.26(2.51)$ & $6.41(5.36)$ & 16.29 & .000 & {$[3.65 ; 4.65]$} & -0.992 \\
\hline Internalizing problems & $12.48(7.22)$ & $19.82(10.86)$ & 14.23 & .000 & {$[6.33 ; 8.36]$} & -0.796 \\
\hline Externalizing problems & $9.05(6.18)$ & $18.06(10.99)$ & 17.25 & .000 & {$[7.98 ; 10.03]$} & -1.012 \\
\hline Total problems & $35.60(18.89)$ & $62.93(32.06)$ & 17.95 & .000 & {$[24.34 ; 30.33]$} & -1.039 \\
\hline Number of sports & $1.03(1.28)$ & $1.11(0.05)$ & -0.14 & .888 & {$[-0.11 ; 0.10]$} & -0.088 \\
\hline Mean of participation in sports & $2.00(0.43)$ & $2.12(0.49)$ & 2.17 & .033 & {$[0.01 ; 0.24]$} & -0.260 \\
\hline Mean of skills in sports & $2.27(0.39)$ & $2.29(0.42)$ & 0.60 & .551 & {$[-0.07 ; 0.12]$} & -0.049 \\
\hline Number of hobbies & $1.11(1.28)$ & $1.27(1.17)$ & 2.90 & .004 & {$[0.05 ; 0.27]$} & -0.130 \\
\hline Mean of participation in hobbies & $2.23(0.45)$ & $2.38(0.47)$ & 3.27 & .001 & {$[0.06 ; 0.24]$} & -0.326 \\
\hline Mean of skills in hobbies & $2.34(0.42)$ & $2.47(0.39)$ & 3.37 & .001 & {$[0.05 ; 0.21]$} & -0.321 \\
\hline Number of chores & $0.87(1.15)$ & $1.49(1.16)$ & 11.15 & .000 & {$[0.51 ; 0.72]$} & -0.537 \\
\hline Mean chores' quality & $2.25(0.47)$ & $2.46(0.44)$ & 5.38 & .000 & {$[0.13 ; 0.29]$} & -0.461 \\
\hline Number of clubs & $0.39(0.72)$ & $0.33(0.60)$ & -2.12 & .035 & {$[-0.12 ; 0.01]$} & 0.091 \\
\hline Mean of participation in clubs & $2.45(0.50)$ & $2.17(0.55)$ & -1.27 & .261 & {$[-0.86 ; 0.29]$} & 0.533 \\
\hline Number of close friends & $2.28(0.79)$ & $2.35(0.72)$ & 2.10 & .036 & {$[0.01 ; 0.14]$} & -0.093 \\
\hline Frequency of contact with friends & $1.55(0.64)$ & $1.68(0.47)$ & 5.33 & .000 & {$[0.08 ; 0.18]$} & -0.232 \\
\hline Behavior with brothers & $1.17(0.78)$ & $0.75(0.63)$ & -13.54 & .000 & {$[-0.48 ;-0.36]$} & 0.592 \\
\hline Behavior with parents & $2.44(0.59)$ & $0.64(0.48)$ & -70.94 & .000 & {$[-1.85 ;-1.75]$} & 3.347 \\
\hline Behavior with others & $2.42(0.62)$ & $0.55(0.50)$ & -74.17 & .000 & {$[-1.92 ;-1.82]$} & 3.320 \\
\hline Behavior alone & $2.33(0.64)$ & $0.52(0.50)$ & -69.96 & .000 & {$[-1.86 ;-176]$} & 3.152 \\
\hline Mean academic performance & $2.19(0.48)$ & $1.99(0.66)$ & -3.96 & .000 & {$[-0.30 ;-0.10]$} & 0.347 \\
\hline
\end{tabular}

\section{Discussion}

The findings of the current study support previous evidence that children and adolescents in RC are dealing with more internalizing, externalizing and total problems than children and adolescents living with their own families (e.g. Erol et al., 2010; Gearing et al., 2014). Furthermore, adolescents in RC seem to be more involved in sports and hobbies, which can be understood as RC centers are more available to engage them in after school activities in the community (e.g. Fernández-Daza \& Fernández-Parra, 2012). Moreover, adolescents in care have more hobbies than those living with their own families. They, therefore, practice more sports, read more and play more games (Sãfvenbom \& Sandahl, 2000 ), potentially because RC programs focus on promoting these activities as protective factors.

Adolescents in RC perform more household chores and think they do so better than adolescents belonging to the normative sample, as found in Fernández-Daza and FernándezParra (2012). Indeed, it appears that RC centers may give more responsibility to adolescents in term of house-keeping than is typical for adolescents in the community. Thus, the way RC is organized and structured seems to inhibit emotional and behavioral problems, allowing adolescents to 
Table 3 Gender differences in self-report measures

\begin{tabular}{|c|c|c|c|c|c|c|}
\hline & $\begin{array}{l}\text { Female } \\
(\mathrm{N}=222) \\
\text { Mean }(\mathrm{SD})\end{array}$ & $\begin{array}{l}\text { Male } \\
(\mathrm{N}=221) \\
\text { Mean }(\mathrm{SD})\end{array}$ & $t(441)$ & $p$ & $95 \% \mathrm{CI}$ & $d$ \\
\hline Anxiety/depression & $9.66(5.02)$ & $7.16(5.03)$ & 5.23 & .000 & {$[1.56 ; 3.44]$} & 0.598 \\
\hline Withdrawal/depression & $6.48(3.08)$ & $5.53(3.12)$ & 3.23 & .001 & {$[0.37 ; 1.53]$} & 0.306 \\
\hline Somatic complaints & $6.52(4.13)$ & $4.29(3.90)$ & 5.85 & .000 & {$[1.48 ; 2.98]$} & 0.555 \\
\hline Social problems & $5.05(3.69)$ & $5.16(4.04)$ & -0.29 & .772 & {$[-0.83 ; 0.82]$} & -0.028 \\
\hline Thought problems & $7.23(4.65)$ & $6.07(4.92)$ & 2.55 & .011 & {$[0.27 ; 2.05]$} & 0.242 \\
\hline Attention problems & $7.44(3.55)$ & $6.60(3.78)$ & 2.40 & .017 & {$[0.15 ; 1.52]$} & 0.229 \\
\hline Rule-breaking behavior & $6.53(4.78)$ & $8.30(5.59)$ & -3.58 & .000 & {$[-2.74 ;-0.80]$} & -0.340 \\
\hline Aggressive behavior & $10.92(6.02)$ & $10.37(7.10)$ & 0.88 & .377 & {$[-0.68 ; 1.78]$} & 0.084 \\
\hline Affective problems & $8.88(5.02)$ & $7.08(5.03)$ & 3.76 & .000 & {$[0.86 ; 2.73]$} & 0.358 \\
\hline Anxiety problems & $4.72(2.35)$ & $3.86(2.36)$ & 3.84 & .000 & {$[0.42 ; 1.30]$} & 0.365 \\
\hline Somatic problems & $3.91(3.08)$ & $2.44(2.94)$ & 5.13 & .000 & {$[0.90 ; 2.03]$} & 0.488 \\
\hline Attention deficit/hyperactivity problems & $5.96(3.02)$ & $5.60(3.17)$ & 1.22 & .225 & {$[-0.22 ; 0.94]$} & 0.116 \\
\hline Oppositional defiant problems & $3.87(2.12)$ & $3.63(2.38)$ & 1.11 & .268 & {$[-0.18 ; 0.66]$} & 0.106 \\
\hline Conduct problems & $5.64(4.72)$ & $7.18(5.85)$ & -3.04 & .002 & {$[-2.53 ;-0.54]$} & -0.290 \\
\hline Internalizing problems & $22.66(10.36)$ & $16.98(10.62)$ & 5.70 & .000 & {$[3.72 ; 7.64]$} & 0.541 \\
\hline Externalizing problems & $17.45(9.90)$ & $18.67(11.98)$ & -1.16 & .245 & {$[-3.27 ; 0.84]$} & -0.111 \\
\hline Total problems & $66.18(28.99)$ & $59.67(34.62)$ & 2.14 & .033 & {$[0.54 ; 12.47]$} & 0.204 \\
\hline Number of sports & $0.96(1.12)$ & $1.09(1.08)$ & -1.29 & .197 & {$[-0.34 ; 0.70]$} & -0.118 \\
\hline Mean of participation in sports & $2.07(0.51)$ & $2.18(0.48)$ & -0.93 & .355 & {$[-0.33 ; 012]$} & -0.222 \\
\hline Mean of skill in sports & $2.30(0.42)$ & $2.30(0.43)$ & -0.09 & .993 & {$[-0.34 ; 0.07]$} & 0 \\
\hline Number of hobbies & $1.24(1.20)$ & $1.30(1.14)$ & -0.50 & .618 & {$[-0.27 ; 0.16]$} & -0.051 \\
\hline Mean of participation in hobbies & $2.38(0.44)$ & $2.38(0.50)$ & 0.49 & .961 & {$[-0.18 ; 0.19]$} & 0 \\
\hline Mean of skill in hobbies & $2.45(0.39)$ & $2.49(0.39)$ & -0.44 & .661 & {$[-0.19 ; 0.12]$} & -0.103 \\
\hline Number of chores & $1.62(1.14)$ & $1.35(1.17)$ & 2.41 & .017 & {$[0.05 ; 0.48]$} & 0.234 \\
\hline Mean chores quality & $2.50(0.42)$ & $2.41(0.46)$ & 1.16 & .248 & {$[-0.06 ; 0.25]$} & 0.204 \\
\hline Number of clubs & $0.22(0.49)$ & $0.44(0.68)$ & -3.88 & .000 & {$[-0.33 ;-0.11]$} & -0.371 \\
\hline Mean of participation in clubs & $2.00(0.59)$ & $2.20(0.61)$ & -0.30 & .778 & {$[-2.04 ; 1.64]$} & 0 \\
\hline Number of close friends & $2.25(0.73)$ & $2.46(0.69)$ & -2.92 & .004 & {$[-0.34 ;-0.07]$} & -0.296 \\
\hline Frequency of contact with friends & $1.67(0.47)$ & $1.69(0.47)$ & -0.28 & .779 & {$[-0.11 ; 0.08]$} & -0.043 \\
\hline Behavior with brothers & $0.64(0.64)$ & $0.85(0.60)$ & -3.40 & .001 & {$[-0.33 ;-0.09]$} & -0.339 \\
\hline Behavior with parents & $0.55(0.50)$ & $0.71(0.45)$ & -3.14 & .002 & {$[-0.26 ;-0.06]$} & -0.336 \\
\hline Behavior with others & $0.49(0.50)$ & $0.61(0.49)$ & -2.38 & .018 & {$[-0.22 ;-0.02]$} & -0.242 \\
\hline Behavior alone & $0.47(0.50)$ & $0.57(0.50)$ & $-1.93^{\dagger}$ & .055 & {$[-0.20 ; 0.01]$} & -0.200 \\
\hline Mean academic performance & $1.98(0.61)$ & $2.00(0.72)$ & -0.26 & .798 & {$[-0.23 ; 0.18]$} & -0.030 \\
\hline
\end{tabular}

develop their own skills and interests (Marinlovic \& Backovic, 2007). Nevertheless, in order to maximize the opportunities for every child to get involved, it is necessary for the center to carefully consider the individual interests of each and every child..

At a social level, the kind and quantity of social contacts indicates the weakness of the social support network that adolescents have in RC (Eapen, 2009; Rutter, 2000). The present data support Bravo and Del Valle's study (2003) which concluded that adolescents in RC report a higher number of close friends, since they overrate peer relationships due to the limitation of the relationships with family members and the scarcity of individualized interactions with other significant adults, regardless of the high number of adults within reach. It is worth noting that this social network is certainly different from what they really need (Bravo \& del Valle, 2003). Indeed, adolescence is a developmental period in which youngsters increasingly struggle for autonomy. The lack of family support in adolescents in RC is evident when considering the scarceness of contacts with parents and siblings. In the current study, although $89.4 \%$ adolescents have siblings, only $28.2 \%$ are living in the same center. Most adolescents in care lose touch with their brothers and sisters. Sibling relationships, as well as the family 
Table 4 Correlations between self-report measures

\begin{tabular}{llllllllll}
\hline YSR scales & Sports & Hobbies & Chores & Organizations & Friends & Brothers \\
& $r$ & $r$ & $r$ & $r$ & $\begin{array}{l}\text { Parents } \\
r\end{array}$ & $\begin{array}{l}\text { Others } \\
r\end{array}$ & $\begin{array}{l}\text { Academic } \\
r\end{array}$ \\
\hline A/D & -.050 & -.023 & -.005 & -.045 & -.020 & $-.119^{*}$ & $-.148^{* *}$ & $-.121^{*}$ & -.096 \\
W/D & -.060 & -.001 & .002 & $-.105^{*}$ & -.006 & -.091 & -.078 & $-.154^{* *}$ & $-.158^{*}$ \\
SC & -.071 & -.019 & -.040 & -.054 & -.039 & -.087 & $-.111^{*}$ & $-.178^{* *}$ & -.083 \\
SP & -.059 & -.025 & -.091 & -.045 & .046 & -.035 & -.060 & $-.151^{* *}$ & -.139 \\
TP & -.015 & -.045 & -.073 & -.039 & .021 & -.093 & $-.130^{*}$ & -.091 & -.099 \\
AP & -.083 & -.055 & -.057 & -.038 & -.008 & -.058 & $-.151^{* *}$ & $-.139^{* *}$ & $-.287^{* *}$ \\
R-BB & $-.101^{*}$ & $-.124^{* *}$ & $-.255^{* *}$ & -.021 & $.105^{*}$ & -.039 & $-.117^{*}$ & .012 & $-.158^{*}$ \\
AB & -.092 & -.087 & $-.192^{* *}$ & -.047 & .070 & $-.108^{*}$ & $-.180^{* *}$ & -.061 & -.102 \\
IP & -.068 & -.018 & -.017 & -.072 & -.026 & $-.116^{*}$ & $-.135^{*}$ & $-.170^{* *}$ & -.062 \\
EP & $-.104 *$ & $-.112^{*}$ & $-.237^{* *}$ & -.038 & .092 & -.084 & $-.163^{* *}$ & -.030 & -.137 \\
TP & -.079 & -.061 & $-.129 * *$ & -.043 & .032 & -.094 & $-.151^{* *}$ & $-.116^{*}$ & -.134 \\
\hline
\end{tabular}

${ }^{*} p<.05 ;{ }^{* *} p<.01$

visits and contacts, are important protective factors in preventing internalizing problems and mental health symptoms (Álvares \& Lobato, 2013). However, not all family contacts are equally beneficial since contacts that have the greatest positive impact on adolescents are home visits with an overnight stay (Huefner, Pick, Smith, Stevens, \& Mason, 2015).

Adolescents in RC have less contact with significant adults, in general. Thus, the access to a significant caregiver is of utmost importance. Each and every adolescent in care should have a given significant caregiver, capable of playing a role in recovering from trauma and promoting positive change (Bravo \& del Valle, 2003). In the present study, only half of the participants were able to identify a significant care giver with whom they could establish a close, trustworthy and meaningful relationship.

When living in $\mathrm{RC}$, adolescents reported feeling less capable of performing tasks on their own than did their normative peers. This can be understood considering their previous traumatic experiences and/or their lack of privacy, seeing that they are constantly in the company of others and do not have the chance of being on their own when solving problems. Academically, adolescents in RC show a poorer achievement, as in Fernández-Daza and Fernández-Parra (2012) who argue that this poor academic achievement is conditioned by functional deficits associated to previous traumatic experiences and RC structural neglect.

Female adolescents showed higher levels of psychopathology and behavior problems than male adolescents, as in Baker et al. (2007) who also reported less psychological adjustment in girls in RC. This may imply that females in $\mathrm{RC}$ have special needs arising from greater trauma histories (e.g., commercial sexual exploitation). Gender differences in emotional and behavioral problems were also found in other studies explaining them as outcomes of developmental differences between boys and girls. Girls mature physically sooner than boys and are more focused in emotional experiences (Abad et al., 2002), but the maturation of the parts of the brain dealing with executive functioning continues into the early $20 \mathrm{~s}$. Not all RC contexts favor the development of significant emotional experiences. As in the normative sample, girls in RC tend to perform more household chores and boys seem to have more social contacts, accounting for overall gender differences (Broberg et al., 2001).

The present study showed that having fewer mental health problems in adolescents was associated with more involvement in sports, hobbies, and a better social network, just as is found in other normative samples (e.g. Achenbach et al., 2002). Thus, female adolescents, who are less involved in sports activities, tend to present more total problems and less psychosocial skills than males. Indeed sports and hobbies are negatively correlated with oppositional defiant behavior and externalizing problems, as these activities tend to promote higher levels of resilience and decrease the probability of delinquent behaviors (Sãfvenbom \& Sandahl, 2000). More involvement in household chores is also negatively correlated with oppositional defiant and aggressive behavior, externalizing problems, as well as the total number of problems. This supports the view that adolescents involved in the RC center's dynamics tend to show less mental health symptoms, seeing that their perception of higher care quality works as a protective factor.

Furthermore, adolescents who are more engaged in clubs in the community have more socialization opportunities with peers and show less signs of withdrawal/depression. This may be due to a healthier life style that is in fact closer to that of their peers in the community (Fernández-Daza \& Fernández-Parra, 2012). Conversely, the total number of friends is positively correlated with oppositional defiant behavior. In order to understand this finding, it is worth considering the kind of friends and peer groups of the adolescents in $\mathrm{RC}$, 
since Erickson et al. (2000) pointed out that adolescents with high levels of psychological maladjustment tend to hang out with deviant groups. In order to be effective, RC programs need to be aware of this dynamic and limit youths' exposure to negative peer influence.

Psychosocial skills are protective factors promoting adjusted coping strategies to emotional problems (Sandoval et al., 2006). Close contacts with siblings, parents and other significant adults are negatively correlated with emotional and behavioral problems. Accordingly, RC centers should promote regular family visits (especially overnight stays), namely with parents and siblings (Huefner et al., 2015). A significant caregiver should also be appointed to each child in care so as to support and establish an individualized relationship with him/her (Bravo \& del Valle, 2003).

\section{Limitations}

There were several limitations in this study, such as, a possible bias associated with social desirability inherent to selfreport measures. A multi-informant study, including caregivers and teachers besides the adolescents themselves, would reduce this limitation. Still, the present study is innovative, since it characterizes adolescents in RC according to their emotional and behavioral problems as well as their skills and developmental opportunities. A second limitation is related to using only one data time point, which merely allows for a picture of how they are doing during their stay, and not how they are doing now relatively to the problems they were experiencing when they were placed in RC. Nevertheless, this study is part of a broader research on RC quality and data from children and adolescents in RC is critical to an evaluation of the degree in which the resources and services provided by $\mathrm{RC}$ centers fit the children and adolescents' needs and characteristics. So, assessment of children's needs and RC services must be made simultaneously at a given moment.

\section{Conclusions and Implications for Practice}

The implementation of policies and practices to enhance RC quality is critical for the promotion of the best development of children in care (Eapen, 2009). First and foremost, the initial pre-service and subsequent in-service training of caregivers should promote skills to create a healthy and safe environment for the child to grow up in. Caregivers should also be able to promptly identify the children's social and emotional needs. Lastly, RC centers should mirror a family environment (family-style programming) by eliminating institutional structural and functional characteristics. This involves particular attention to each child as an individual, with needs, strengths and difficulties, life goals and interests (Eapen, 2009).

Overall, the findings of this study highlight the need of an early screening of socio-cognitive deficits and strengths in children in care in order to allow for the implementation of efficient socio-educational programs (Ison-Zintilini \& Morelato-Giménez, 2008; Reijneveld et al., 2005). The higher levels of challenges faced by girls entering RC likely indicates that they are particularly vulnerable and deserve gender-specific interventions and attention.

A strong emphasis in recommending the promotion of socialization opportunities with significant others (siblings, parents, relatives, care givers, peers) for children in RC appears to be an important output of the current study, since these social interactions act as protective factors for the child's mental health. Having access to the community environment that surrounds them and building a solid support network will enhance the child's wellbeing, psychological adjustment. RC contexts should be high quality, caring and safe environments. Procedures to systematically assess RC quality must be implemented both internally and externally ensuring the child's best interests.

Funding Funding was provided by Foundation for a Science and Technology (Grant No. PD/BD/114267/2016).

\section{References}

Abad, J., Forns, M., \& Gómez, J. (2002). Emotional and behavioral problems as measured by YSR: Gender and age differences in Spanish adolescents. European Journal of Psychological Assessment, 18, 149-157. https://doi.org/10.1027//1015-5759.18.2.157.

Achenbach, T., Dumenci, L., \& Rescorla, L. (2002). Ten-year comparisons of problems and competencies for national samples of youth: Self, parent, and teacher reports. Journal of Emotional and Behavioral Disorders, 10(4), 194-203. https://doi.org/10.1177/10634 266020100040101.

Achenbach, T., \& Rescorla, L. (2001). Manual for the ASEBA school age forms \& profiles. Burlington: University of Vermont, Research Centre for Children, Youth, \& Families.

Achenbach, T., Rescorla, L., Dias, P., Ramalho, V., Sousa Lima, V., Machado, B., \& Gonçalves, M. (2014). Manual do Sistema de Avaliação Empiricamente Validado (ASEBA) para o Período PréEscolar e Escolar. Braga: Psiquilibrios Edições.

Álvares, A., \& Lobato, G. (2013). Um estudo exploratório da incidência de sintomas depressivos em crianças e adolescentes em acolhimento residencial [Exploratory study on the prevalence of depressive symptoms in children and adolescents in care]. Temas em Psicologia, 21(1), 151-164. https://doi.org/10.9788/TP2013.1-11.

Appleyard, K., Egeland, B., van Dulmen, M. H., \& Sroufe, L. A. (2005). When more is not better: The role of cumulative risk in child behavior outcomes. Journal of Child Psychology and Psychiatry, 46, 235-245.

Baker, A. L., Archer, M., \& Curtis, P. (2007). Youth characteristics associated with behavioral and mental health problems during the transition to residential treatment centers: The Odyssey Project population. Child Welfare League of America, 86(6), 5-29. 
Behen, M., Helder, E., Rothermel, R., Solomon, K., \& Chugani, H. (2008). Incidence of specific absolute neurocognitive impairment in globally intact children with histories of early severe deprivation. Child Neuropsychology, 14(5), 453-469. https:// doi.org/10.1080/09297040802244136.

Bravo, B., \& del Valle, J. (2003). Las redes de apoyo social de los adolescentes acogidos en residencias de protección. Un análisis comparativo com población normative [Social support networks of adolescents in residential care centers. A comparative analysis with normative population]. Psicothema, 15(1), 136-142.

Broberg, A., Ekeroth, K., Gustafsson, P., Hansson, K., Hagglof, B., Ivarsson, T., \& Larsson, B. (2001). Self-reported competencies and problems among Swedish adolescents: A normative study of the YSR. European Child \& Adolescent Psychiatry, 10, 186-193.

Bronsard, G., Lançon, C., Loundou, A., Auquier, P., Rufo, M., \& Siméoni, M. (2011). Prevalence rate of DSM mental disorders among adolescents living in residential group homes of the French Child Welfare System. Children and Youth Services Review, 33(10), 1886-1890. https://doi.org/10.1016/j.childyouth.2011.05.014.

Campbell, S. B., Shaw, D. S., \& Gilliom, M. (2000). Early externalizing behavior problems: Toddlers and preschoolers at risk for later maladjustment. Development and Psychopathology, 12, 467-488. https://doi.org/10.1017/S0954579400003114.

Eapen, D. (2009). Institutionalized children: The underprivileged. International Journal of Nursing Practice, 15(5), 349-352. https ://doi.org/10.1111/j.1440-172X.2009.01785.x.

Erickson, K. G., Crosnoe, R., \& Dornbusch, S. M. (2000). A social process model of adolescent deviance: Combining social control and differential association perspectives. Journal of Youth and Adolescence, 29, 395-425.

Erol, N., Simsek, Z., \& Munir, K. (2010). Mental health of adolescents reared in institutional care in Turkey: Challenges and hope in the twenty-first century. European Child \& Adolescent Psychiatry, 19, 113-124. https://doi.org/10.1007/s00787-009-0047-2.

Fernández-Daza, M., \& Fernández-Parra, A. (2012). Problemas de comportamiento y competencias psicossociales en niños y adolescentes institucionalizados [Behavior problems and psychosocial skills in institutionalized children and adolescents]. Universitas Psychologica, 12(3), 797-810. https://doi.org/10.11144/Javeriana. UPSY12-3.pccp.

Gearing, R., Schwalbe, C., MacKenzie, M., Brewer, K., \& Ibrahim, R. (2014). Assessment of adolescent mental health and behavioral problems in institutional care: Discrepancies between staffreported CBCL scores and adolescent-reported YSR scores. Administration and Policy in Mental Health and Mental Health Services Research, 42(3), 279-287. https://doi.org/10.1007/s1048 8-014-0568-y.

Gutman, L. M., Sameroff, A. J., \& Cole, R. (2003). Academic growth curve trajectories from 1 st grade to 12 th grade: Effects of multiple social risk factors and preschool child factors. Developmental Psychology, 39, 777-790. https://doi. org/10.1037/0012-1649.39.4.777.

Huefner, J. C., Pick, R. M., Smith, G. L., Stevens, A. L., \& Mason, M. A. (2015). Parental involvement in residential care: Distance, frequency of contact, and youth outcomes. Journal of Child and Family Studies, 24, 1481-1489. https://doi.org/10.1007/s1082 6-014-9953-0.

Huefner, J. C., Ringle, J. L., Thompson, R. W., \& Wilson, F. A. (2018). Economic evaluation of residential length of stay and long-term outcomes. Residential Treatment for Children \& Youth, 35(3), 192-208. https://doi.org/10.1080/0886571X.2018.1437375.

IBM Corp. Released 2014. IBM SPSS statistics for windows, version 22.0. Armonk, NY: IBM Corp.

Instituto da Segurança Social, Instituto Público (ISS, IP). (2018). CASA 2017: Caracterização Anual da Situação de Acolhimento das Crianças e Jovens [Annual characterization of care situation of children and adolescents]. Lisboa: ISS, IP.

Ison-Zintilini, M., \& Morelato-Giménez, G. (2008). Habilidades sociocognitivas en niños con conductas disruptivas y víctimas de maltrato [Socio-cognitive skills in children with disruptive behavior and victims of maltreatment]. Universitas Psychologica, 7(2), 357-367.

Janssens, A., \& Deboutte, D. (2009). Screening for psychopathology in child welfare: The Strengths and Difficulties Questionnaire (SDQ) compared with the Achenbach System of Empirically Based Assessment (ASEBA). European Child \& Adolescent Psychiatry, 18, 691-700. https://doi.org/10.1007/s00787-009-0030-y.

Jozefiak, T., Kayed, N., Rimechaug, T., Wormdal, A., Brubakk, A., \& Wichstram, L. (2016). Prevalence and comorbidity of mental disorders among adolescents living in residential youth care. European Child \& Adolescent Psychiatry, 25, 33-47. https://doi. org/10.1007/s00787-015-0700-x.

Kjelsberg, E., \& Nygren, P. (2004). The prevalence of emotional and behavioural problems in institutionalized childcare clients. Nordic Journal of Psychiatry, 58, 319-325. https://doi.org/10.1080/08039 480410005846.

Larson, R., \& Kleiber, D. (1993). Structured leisure as a context for the development of attention during adolescence. Society and Leisure, 16, 77-98. https://doi.org/10.1080/07053436.1993.10715443.

Lei ${ }^{\circ} 142 / 2015$ de 8 de Setembro de 2015 [Law 142/2015, 8th September].

Mäntymaa, M., Puura, K., Luoma, I., Latva, R., Salmelin, R., \& Tamminen, T. (2012). Predicting internalizing and externalizing problems at five years by child and parental factors in infancy and toddlerhood. Child Psychiatry \& Human Development, 43, 153-170. https://doi.org/10.1007/s10578-011-0255-0.

Marinlovic, J., \& Backovic, D. (2007). Relationship between type of placement and competencies and problem behavior of adolescents in long-term foster care. Children and Youth Services Review, 29, 216-225. https://doi.org/10.1016/j.childyouth.2006.08.004.

Oliván, G. (2002). Maltreatment histories and mental health problems are common among runaway adolescents in Spain. Acta Paediatrica, 91, 1274-1275. https://doi.org/10.1111/j.1651-2227.2002. tb00148.x.

Reijneveld, S., Brugman, E., Verhulst, F., \& Verloove-Vanhorick, S. (2005). Area deprivation and child psychosocial problems: A national cross-sectional study among school-aged children. Social Psychiatry and Psychiatric Epidemiology, 40, 18-23. https://doi. org/10.1007/s00127-005-0850-0.

Rodrigues, S., Barbosa-Ducharne, M., \& Del Valle, J. F. (2015). ARQUA-P: Sistema Compreensivo de Avaliação da Qualidade do Acolhimento Residencial Português@. [Portuguese Comprehensive Assessment System of Residential Care Quality]. Registo 2650/2015. Lisboa: Secretaria de Estado da Cultura, InspeçãoGeral das Atividades Culturais - Direção de Serviços de Propriedade Intelectual.

Rutter, M. (2000). Children in substitute care: Some conceptual considerations and research implications. Children and Youth Services Review, 22(9), 685-703. https://doi.org/10.1016/S0190 -7409(00)00116-X.

Sãfvenbom, R., \& Sandahl, D. (2000). Leisure for youth in residential care: An important context for intervention. International Journal of Social Welfare, 9, 120-127. https://doi.org/10.1111/14682397.00117.

Sandoval, M., Lemos, S., \& Vallejo, G. (2006). Self-reported compentencies and problems in Spanish adolescents: A normative study of the YSR. Psicothema, 18(4), 804-809.

Schmid, M., Goldbeck, L., Nuetzel, J., \& Fegert, J. (2008). Prevalence of mental disorders among adolescents in German youth welfare institutions. Child and Adolescents Psychiatry and Mental Health, 2(2), 1-8. https://doi.org/10.1186/1753-2000-2-2. 
Sempik, J., Ward, H., \& Darker, I. (2008). Emotional and behavioural difficulties of children and young people at entry into care. Clinical Child Psychology and Psychiatry, 13(2), 221-233. https://doi. org/10.1177/1359104507088344.

Simms, M., Dubowitz, H., \& Szilagyi, M. A. (2000). Health care needs of children in the foster care system. Pediatrics, 106, 909-918.

Simsek, Z., Erol, N., Oztop, D., \& Munir, K. (2007). Prevalence and predictors of emotional and behavioral problems reported by teachers among institutionally reared children and adolescents in Turkish orphanages compared with community controls. Children and Youth Services Review, 29(7), 883-899. https://doi. org/10.1016/j.childyouth.2007.01.004.
Smyke, A., Zeanah, C., Fox, N., Nelson, C., \& Guthrie, D. (2010). Placement in foster care enhances quality of attachment among young institutionalized children. Child Development, 81(1), 212223. https://doi.org/10.1111/j.1467-8624.2009.01390.x.

Publisher's Note Springer Nature remains neutral with regard to jurisdictional claims in published maps and institutional affiliations. 